\title{
ANÁLISE DA ESTÉTICA DO CONCRETO PRODUZIDO COM REJEITO PLÁSTICO PARA O USO NO DESIGN DE INTERIORES COM VIÉS SUSTENTÁVEL
}

\section{ANALYSIS OF AESTHETICS OF CONCRETE PRODUCED WITH PLASTIC REJECT FOR USE IN SUSTAINABLE INTERIOR DESIGN}

BIBIANA WITTMANN LANZARIN, M.Sc.| UNIRITTER

LUIS FERNANDO FOLLE, Dr. | UFRGS

\begin{abstract}
RESUMO
O concreto é amplamente utilizado devido a sua relação entre custo e benefício: nenhum outro material de construção apresenta essas duas vantagens concomitantemente. Entretanto, o uso excessivo de concreto na construção civil é responsável por um aumento na produção e transporte de cimento. Além desta desvantagem, o aumento na geração de resíduos e na exploração de recursos naturais advindos da produção do material é um problema progressivo e, consequentemente, o equilíbrio ecológico é afetado negativamente. $O$ objetivo deste trabalho é avaliar a estética do concreto produzido com rejeito plástico reciclado, para uso em objetos de decoração e móveis do Design de Interiores. A proposta une o reaproveitamento destes materiais plásticos que são problemáticas para a sociedade e a diminuição dos resíduos de cimento. Para isso, realizou-se uma breve análise da ressignificação do uso do concreto como elemento não só estrutural, mas com valor estético, nos projetos de interiores onde são apresentados conceitos sobre sustentabilidade e desenvolvimento sustentável, bem como questões sobre descarte e reciclagem de plásticos. A metodologia utilizada incluiu a preparação do concreto com diferentes proporções de resíduo plástico, preparação dos corpos de prova e posteriormente testes realizados em laboratório para verificar a perda de massa e porosidade da peça produzida, com a finalidade de utilização. Os resultados indicam que o estudo contribui para a diminuição de resíduos plásticos, produzindo um material que seja equilibrado ecologicamente e de estética satisfatória quando comparado ao concreto sem adição de rejeitos plásticos.
\end{abstract}

PALAVRAS CHAVE: Concreto com resíduos. Sustentabilidade. Plástico. Design de Interiores. Descarte.

\begin{abstract}
Concrete is widely used because of its cost-benefit ratio: no other building material concomitantly has these two advantages. However, excessive use of concrete in construction is responsible for an increase in cement production and transportation. In addition to this disadvantage, the increase in waste generation and the exploitation of natural resources from material production is a progressive problem and, consequently, the ecological balance is negatively affected. The aim of this work is to evaluate the aesthetics of concrete produced with recycled plastic waste, for use in interior design and furniture objects. The proposal unites the reuse of these plastic materials that are problematic for society and the reduction of cement waste. To this end, a brief analysis of the reframing of the use of concrete as not only structural, but with aesthetic value, was carried out in interior projects where concepts about sustainability and sustainable development are presented, as well as issues about plastic disposal and recycling. The methodology used included the preparation of concrete with different proportions of plastic waste, preparation of specimens and later tests performed in the laboratory to verify the loss of mass and porosity of the produced part, for the purpose of use. The results indicate that the study contributes to the reduction of plastic waste, producing a material that is ecologically balanced and of satisfactory aesthetics when compared to concrete without the addition of plastic waste.
\end{abstract}

KEY WORDS: Concrete with waste. Sustainability. Plastic. Interior Design. Discard. 


\section{INTRODUÇÃO}

Para além de um material exclusivamente estrutural, o concreto passou a ser utilizado como revestimento em estruturas com concreto aparente, assim como na produção de móveis e objetos de decoração. $\mathrm{O}$ concreto aparente encontra-se em construções e revestimentos de estilo moderno e industrial, englobando conceitos de sustentabilidade, pois, assim, evita o uso de revestimentos cerâmicos, rejunte, massa corrida e tintas, por exemplo. Os móveis e objetos de decoração produzidos com concreto aparecem, muitas vezes, como advento das mídias digitais, nos formatos 'faça você mesmo' (do inglês DIY - do it yourself), porém, grandes redes de distribuição já adotaram esse fenômeno e passaram a comercializá-lo pronto.

Com uma preocupação não só estética, mas também ligada a questões de sustentabilidade, este estudo busca a reutilização de material plástico oriundo de descarte indevido e de rejeito produzido pela indústria para propor a produção de um material mais sustentável, mais leve e com aparência semelhante ao concreto produzido sem adição de rejeitos.

Os ecossistemas mundiais estão sob pressão, à sociedade consome recursos que não podem ser repostos, a poluição cresce ano após ano, assim como a degradação ambiental. A Terra corre risco de esgotamento de suas capacidades de absorção da poluição devido ao seu aumento latente. Está evidente a dificuldade em prover os recursos necessários para a vida no planeta paralela à ação humana de degradação constante. Diante deste cenário, é necessária uma mudança no paradigma atual e uma adoção de estratégias que não aumentem o desgaste e sejam uma alternativa viável para a manutenção dos confortos já adquiridos

A ressignificação do uso do concreto como elemento não só estrutural, mas com valor estético, nos projetos de interiores é apresentada a partir de projetos, divulgação em revistas comerciais da área, blogs, e apresentação de designers que produzem móveis e objetos de decoração a partir do uso de concreto. Da mesma forma, expõem-se conceitos necessários sobre sustentabilidade e desenvolvimento sustentável, bem como questões sobre descarte e reciclagem de plásticos e um estudo sobre a sustentabilidade na construção de edificações. Ao mesmo tempo em que a construção civil produz grande quantidade de resíduos, ela também apresenta possibilidades de reuso de diferentes tipos de rejeito. Apesar de ser utilizado neste estudo com outro viés, o concreto é um elemento essencialmente utilizado na construção civil e faz-se necessário contextualizá-lo no seu espaço de origem.

A metodologia utilizada inclui experimento envolvendo a preparação do concreto com diferentes proporções de resíduo de sacolas plásticas, preparação dos corpos de prova e posteriormente testes realizados em laboratório para verificar as propriedades de perda de peso próprio e porosidade da peça produzida, com a finalidade de utilização em projetos de interiores.

Buscou-se, então, neste estudo contribuir com a produção de um material capaz de reaproveitar rejeitos plásticos que, muitas vezes, acabam por ser descartados de maneira indevida em aterros sanitários.

\section{CONCRETO NO DESIGN DE INTERIORES}

Para demonstrar o uso do concreto no design de interiores como fenômeno atual, buscou-se referências em produção e divulgação de conteúdo, em uma plataforma de compartilhamento de vídeos, o YouTube, e revistas comerciais da área. Verificou-se o uso predominante de argamassas, tintas de efeito concreto, e também de rejeitos, como proposto neste estudo.

Foram analisados 105 vídeos compartilhados no YouTube desde 2015, através do uso das tags 'concreto' e 'DIY' e então, foram assistidos os primeiros 105 vídeos. Conforme apêndice $\mathrm{A}$, os dados analisados foram: data, produtor de conteúdo, produto produzido, material utilizado e tempo de cura. Os vídeos foram publicados entre os anos de 2015 até início de 2019, sendo três deles de 2015, 28 vídeos de 2016, 37 do ano de 2017, 31 de 2018 e 6 vídeos do ano de 2019.

O uso da argamassa aparece em oitenta e nove dos vídeos analisados. Em alguns casos, foram realizadas misturas de argamassa com cimento e isopor, propondo a reutilização deste material. Os objetos produzidos são diversos, como bancos (Figura 1), luminárias, vasos (Figura 2), relógios (Figura 3), mesas, entre outros. O tempo de cura é variado, porém predominam os tempos de $24 \mathrm{~h}$ e $48 \mathrm{~h}$, representando $65 \%$ dos vídeos analisados, enquanto 14\% não informa o tempo de cura respeitado.

A coleta de dados em revistas comerciais da área foi realizada nos websites das revistas Casa Vogue e Minha Casa, as quais são voltadas à decoração de interiores e arquitetura. A busca de dados ocorreu através das publicações realizadas nos sites oficiais e que evidenciaram o uso do concreto aparente. No website da Casa Vogue através da opção pesquisar, foram encontrados cerca de 400 postagens citando concreto, concreto aparente e cimento queimado. Dentre as diversas publicações que apresentam o concreto como elemento decorativo e estrutural, associado ao estilo industrial, em apartamentos e casas de diferentes metragens, a publicação que mais chamou atenção foi a intitulada Cenoura, que apresenta um estudo realizado na Universidade de Lancaster com a utilização de partículas vegetais como aditivos na produção de concreto com o objetivo de aumentar a 
resistência do concreto. A utilização dessas partículas reduziria o uso de cimento e, automaticamente, o consumo de energia e emissão de CO2 (dióxido de carbono).

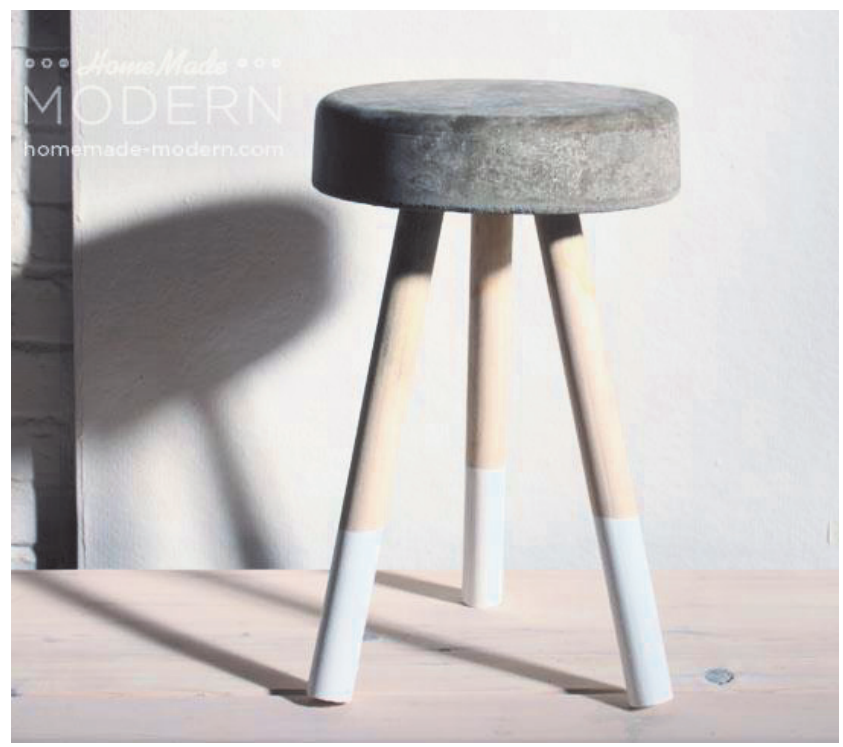

Figura 01 - Banco/mesa lateral com pés de madeira. Fonte: Homemade Modern (2018)

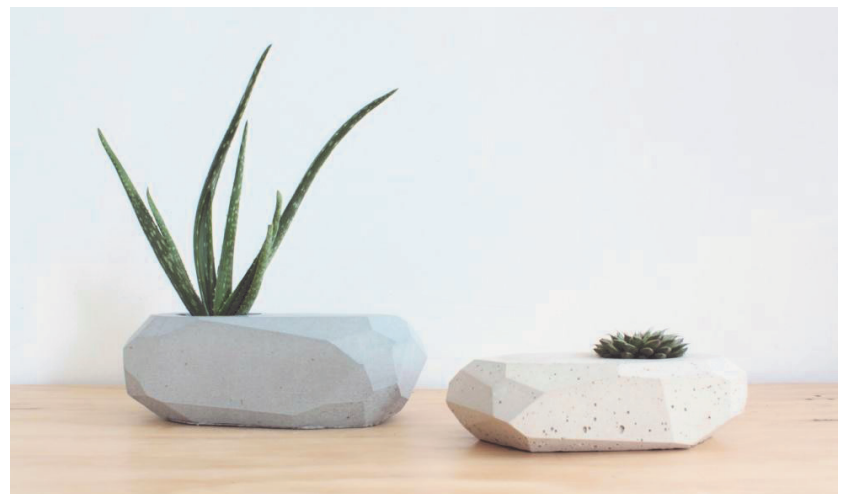

Figura 02 - Vasos de concreto geométricos. Fonte: Homemade Modern (2018)

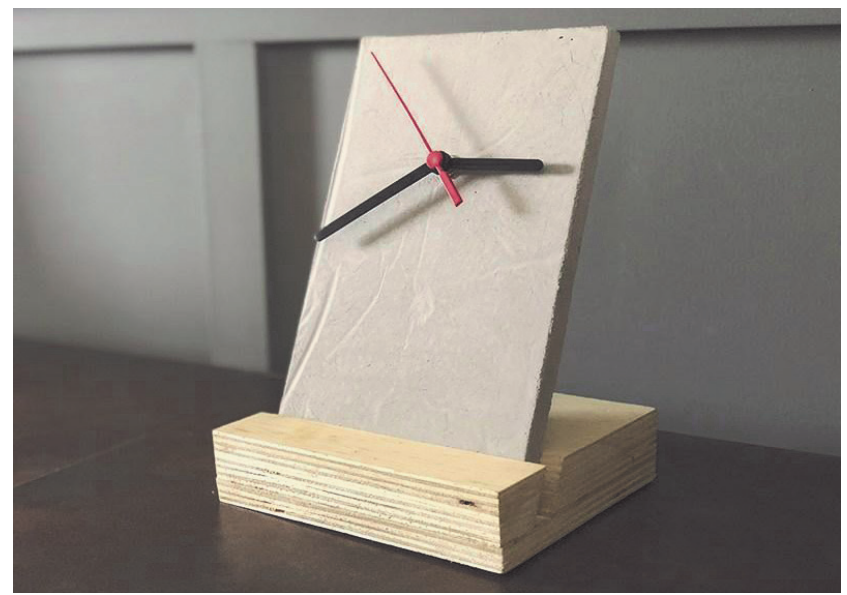

Figura 03 - Relógio de concreto. Fonte: Do Edu (2018)
Ainda sobre este estudo, a publicação cita que, considerando-se o fato da produção do cimento (principal ingrediente do concreto) gerar $\mathrm{CO} 2$ como subproduto de sua reação química, até mesmo uma pequena redução na quantidade de cimento poderia gerar um grande impacto positivo. Para tal, propôs que a utilização de raízes vegetais funcionaria devido a suas nano plaquetas, as quais aumentariam a quantidade de hidrato de silicato de cálcio (substância primária responsável por dar força ao concreto). De acordo com o que apresenta a publicação, este aditivo teria tido um desempenho superior aos aditivos que são apresentados no mercado, gerando uma utilização de $40 \mathrm{~kg}$ a menos de cimento Portland por metro cúbico pelos engenheiros (CHIMELLO, 2018). Estudos como esse, publicados em canais comerciais, evidenciam a preocupação com a produção de material sustentável nos dias de hoje, bem como a crescente utilização do concreto no interior dos espaços residenciais e comerciais, trazendo referências de projetos nacionais e internacionais.

No website da revista Minha Casa, também através do sistema de busca disponível no site, foi encontrada 144 publicações sobre concreto. Dentro do perfil da revista, o concreto aparente se apresenta no uso de blocos de concreto como apoio para móveis e também no uso de tinta efeito, utilizando-se sua estética e não o material em si. E, mesmo de maneira menos elaborada, o concreto aparece em vigas com material aparente, em bancos e em pisos. Vê-se, também, proposta de uso de vasos de concreto para plantas no estilo "faça você mesmo".

\section{SUSTENTABILIDADE}

O conceito da sustentabilidade ganhou destaque na sociedade no fim do século XX, quando o termo voltou a circular a partir da incorporação de novos conceitos relacionados à ecologia e às teorias de sistemas e de complexidade. Ecologia consiste no estudo dos seres vivos e do meio ambiente, podendo ser definido como o estudo das interações entre os organismos e seus ambientes físicos e biológicos. (ROAF; FUENTES; THOMAS-REES, 2014). Esses organismos possuem a capacidade de se adaptar para utilizar os recursos disponíveis em diferentes ambientes, mantendo a vida nos ecossistemas do planeta. O ecossistema, por sua vez, pode ser definido como os fatores que formam o meio ambiente, o ecossistema é parte da ecologia (ROAF; FUENTES; THOMAS-REES, 2014). Isoldi (2007) sintetiza o conceito de ecossistema dispondo que "revela que os elementos da natureza não existem isolados uns dos outros, mas sim tendem a se combinar em sistemas complexos estabelecidos a partir de uma série de relacionamentos físicos e biológicos". 
Conforme Szabo (2005), as noções de sustentabilidade, no princípio, estavam ligadas a questões ambientais, pois foram os acidentes ambientais e a iminência de novos acontecimentos que colocaram o assunto em pauta. Para alcançar um desenvolvimento autossustentável é necessário planejar e reconhecer que os recursos naturais não são infinitos e estabelecer um limite de uso destes recursos naturais (ZYLBERSZTAJN; LINS, 2010).

Posteriormente, o conceito de sustentabilidade alcançou os campos social, cultural, econômico e político, chegando também na arquitetura, na engenharia e na construção civil. No caso da sustentabilidade para a arquitetura, por exemplo, muitos fatores devem ser levados em consideração em um projeto e execução de uma obra, como o impacto ambiental da obra e a possível redução desse impacto, a verificação do entorno, analisando a possibilidade de projetos futuros e do plano urbanístico do espaço, além de estudar questões sobre água, energia, transporte, descarte de lixo, respeito à vegetação existente, entre outros (SZABO, 2005).

A espécie humana está no foco do desenvolvimento sustentável e da sustentabilidade em si. Manter as condições do planeta é fundamental para vida humana, "sustentabilidade é a condição ou estado que permite a continuidade da espécie humana e proporciona uma vida segura, saudável em harmonia com a natureza e com valores locais, culturais e espirituais e, um objetivo a ser alcançado." (ISOLDI, 2007). Para Edwards (2008), muito se fez para definir conceitos sobre o desenvolvimento sustentável, porém pouco se fez para agregar tais conceitos a sociedade.

A compreensão e conscientização sobre os problemas ambientais levaram a novos comportamentos sociais, ou seja, a busca por produtos e serviços de consumo limpo (MANZINI; VEZZOLI, 2005). Para Trigueiro (2003) "uma comunidade humana sustentável deve ser planejada de modo que os estilos de vida, negócios, atividades econômicas, estruturas físicas e tecnológicas não interfiram nessa capacidade da natureza de manter a vida". É preciso sair da zona de conforto, procurar formas de colaborar e orientar novos projetos, envolver a sociedade em um diálogo sobre o contexto em que se vive. Segundo Thackara (2008), é necessário criar relações entre criadores e consumidores já que, para além dos avanços e soluções tecnológicas, a sustentabilidade se refere também a inovação social.

Um desafio para a sustentabilidade está relacionado ao consumo e aos consumidores, que por vezes não associam suas ações a degradação do meio ambiente. Um exemplo simples é o uso da madeira em construções e móveis, causando destruição em massa nas florestas, ou então "quando compramos uma roupa, não pensamos nos agrotóxicos usados na plantação de algodão ou no trabalho escravo encontrado nas fazendas" (TRIGUEIRO, 2012).

No entanto, a noção de sustentabilidade é ampla e complexa e está passando por constantes mudanças, tanto com ampliação quanto com restrição de sentidos. Além disso, o conceito se reflete em distintas áreas, ou seja, é aplicado em diferentes objetos resultando em diferentes visões de sustentabilidade para cada um deles. Entretanto, se faz claro que o objetivo em buscar um crescimento urbano mais sustentável é encontrar uma maneira de continuar suprindo as necessidades da população de uma maneira que as gerações futuras também tenham essa possibilidade (BARROS, 2011).

\subsection{Descarte e reciclagem}

Pensar no descarte dos produtos não é só uma questão ambiental, visto que a poluição da água e o aumento do aquecimento global são fatores que prejudicam também a saúde da população, principalmente quem vive perto ou trabalha em áreas de descarte - devido a emissão de gases metano. (EDWARDS, 2008) A contaminação do solo prejudica a biodiversidade e a produção agrícola, pois a recuperação do solo é uma tarefa complicada e dificilmente será possível produzir alimentos, por exemplo, em um solo contaminado por lixo.

O principal objetivo da reutilização de materiais é diminuir o resíduo produzido por produtos já existentes, além de amenizar o uso de matérias-primas e, a partir da reciclagem, evitar o desperdício propondo o reuso dos materiais descartados. (CÂNDIDO, 2008). De acordo com Platcheck (2003), a reciclagem, por sua vez, é tida como a recuperação dos materiais descartados, modificando suas características físicas, diferenciando-se do reuso de embalagens retornáveis, por exemplo, pois estas mantêm as formas para as quais foram projetadas.

Ressignificar o que conhecemos como lixo é um fator relevante da reciclagem. Existem diferentes formas de coleta e no Brasil podem-se citar os catadores e também a coleta seletiva. Em relação à coleta, Trigueiro (2012) apresenta dados sobre ela no Brasil e acredita que a coleta seletiva seja uma fonte de novas opções de trabalho para essa parcela da população.

Enquanto as cidades seguem em exponencial crescimento, os aterros sanitários, local onde grande parte dos lixos urbanos são destinados, necessitam ser reduzidos. Entretanto, esta não é uma realidade das cidades. Conforme Trigueiro (2012), estima-se que $40 \%$ de todos os resíduos sólidos domésticos que ocupam espaço nos aterros sejam recicláveis. 
A fim de solucionar parcialmente a situação dos aterros tem-se a coleta seletiva, que se propõe a reduzir a quantidade diária de resíduos recicláveis descartados em aterros, para que esses aterros passem a receber, apenas matéria orgânica para quais foram, de fato, pensados. Um dos principais entraves à reciclagem reside no fato de os descartes plásticos se encontrarem contaminados com resíduos orgânicos. Outro problema é a separação dos diferentes tipos de resíduos, muitas vezes incompatíveis entre si (RETO, 2008).

No caso dos materiais de construção, há inúmeras formas de se reutilizar os resíduos descartados, como vigas metálicas, madeira e tijolos que poderiam ser reutilizados em outras construções, por exemplo. Porém a reciclagem ainda é dificultada pelo fato das edificações ainda não serem projetadas de acordo com suas possibilidades de reutilização, segundo Edwards (2008). A redução de resíduos, reuso e reciclagem de materiais é uma prática possível dentro da construção civil, as estruturas de aço são exemplo disso, podem ser utilizadas como elementos estruturais em projetos novos ou então recicladas, a partir da sua fundição (EDWARDS, 2008).

Dentre os materiais presentes na construção civil está o concreto, a argamassa de cal, o aço, a madeira, tijolos, cerâmica, entre outros. O concreto, por exemplo, se executado corretamente, possui longa vida útil e permite reaproveitamento, podendo ser reutilizado como estrutura existente ou pode ser reciclado para o uso como agregado na produção de novas composições de concreto. De acordo com Edwards (2008) o concreto não costuma precisar de acabamentos, reduzindo riscos à saúde, e, por ser estável do ponto de vista ambiental, oferece vantagens de conforto térmico em relação a outras formas de construção.

\subsection{Descarte do plástico}

A composição do plástico é essencial para compreender os processos utilizados no manejo e descarte. A matéria prima é o polímero que é base para produção de diferentes materiais poliméricos, bastando que seja alterado o processo de fabricação ou que sejam feitas diferentes misturas. (MICHAELI et al, 1995).

Embalagens, sejam elas plásticas ou não, continuarão a existir, sendo assim é necessário pensar no processo de reciclagem. Usando dados de 2007, se um terço dos materiais recicláveis fosse reciclado, iria se economizar o total de energia elétrica que é usado por todas as casas de São Paulo (TRIGUEIRO, 2012). Entende-se que há uma grande produção de resíduo, visto que boa parte desses plásticos vão para o lixo comum e, consequentemente, para aterros sanitários, levando muito tempo até sua decomposição. Ainda poderíamos citar os que são descartados em rios, praias e locais que prejudicam ecossistemas como um todo. No que diz respeito às sacolas plásticas, grande preocupação dos ambientalistas, alguns países europeus já adotaram mudanças não só culturais quanto ao seu uso, mas também na sua legislação (TRIGUEIRO, 2012).

Para além de questões de uma possível mudança na legislação, a cultura do uso de sacolas plásticas no Brasil é enorme e está incorporada à rotina de compra. Elas são fornecidas em grande parte do comércio, supermercados, farmácias, seja qual for o tamanho do produto. A questão do uso dessas sacolas é abordada por Trigueiro (2012), trazendo, inclusive, a quantidade média mensal utilizada por cada brasileiro. Trata-se de um valor alarmante quando se pensa no destino que se dá a esse produto após o uso.

Dados atuais informam que $80 \%$ dos resíduos plásticos encontrados nos oceanos surge como lixo urbano, que é levado para o oceano por meio dos rios. (FAIRBANKS, 2019) e, atualmente, segundo o coordenador do Coplast, a reciclagem de plásticos pós-consumo no Brasil está entre 25\% e 30\% (FAIRBANKS, 2019).

As questões apresentadas são base para justificativa das escolhas realizadas nessa pesquisa. Dessa forma, o objetivo é propor, não só uma peça de concreto resistente, mas também uma maneira de incorporar rejeitos encontrados em grande quantidade nas cidades. Sendo assim, uma forma de diminuir os impactos causados pelo descarte indevido desses rejeitos. A seguir a apresentação da metodologia utilizada nesta pesquisa, a fim de contextualizar os métodos utilizados para coleta de dados e técnica de pesquisa.

\section{MATERIAIS E MÉTODOS}

Para realizar este estudo, utilizou-se a argamassa Multimassa - Quartzolit (๑ 2017 Weber, produtos quartzolit - Saint-Gobain.), constituída por um graute pronto elaborado à base de cimento, agregados minerais e aditivos especiais que, quando misturados, resultam num produto de fácil aplicação, sendo necessária apenas a adição de água para a formação da pasta de concreto. Esta opção de material foi escolhida com base em pesquisa realizada para verificar as formas de uso do concreto no design de interiores, na qual percebeu-se uso quase exclusivo de argamassas e produtos prontos.

Verificou-se que a preparação do concreto, não só em obras de pequeno porte, mas também na produção de objetos de decoração, é realizada de maneira empírica. Questões como temperatura e quantidade de água, 
normalmente, não são observadas na prática conforme a indicação da embalagem. Porém, para execução deste estudo, manteve-se a medida de $150 \mathrm{ml} / \mathrm{kg}$ para obter um padrão do concreto produzido.

Para além dos rejeitos plásticos utilizados nos pré-testes, aparas plásticas fornecidas pela empresa Ecoresinas, situada na cidade de Camargo-RS, foram usadas. A empresa é uma recuperadora de plásticos, os materiais fornecidos pela empresa são provenientes de coletas seletivas e os produtos finais a que são destinados são: sacos de lixo, sacolas, mangueiras e lonas.

Estas aparas, quando chegam à empresa, passam por um processo de classificação, em que são retirados os materiais considerados lixo (papel, metais, madeiras, etc.), bem como materiais considerados contaminantes (PVC, PET, etc.). Após a classificação, os materiais passam por um processo mecânico onde são moídos, lavados, secados e triturados. Em seguida, o material passa pelo processo de granulação ou de aglutinamento, formato no qual o material foi recebido para essa pesquisa.

Para a produção do material granulado (Figura 4), ocorre o processo de granulação. Nessa etapa, após o material plástico ser lavado, secado e triturado, é direcionado para uma máquina chamada Extrusora Recicladora, na qual o material plástico sofre um processo de aquecimento e é feita a fusão (derretimento) do plástico. O material plástico derretido (pastoso) e comprimido e, na sequência, sofre um processo de corte, transformando o material em grão.

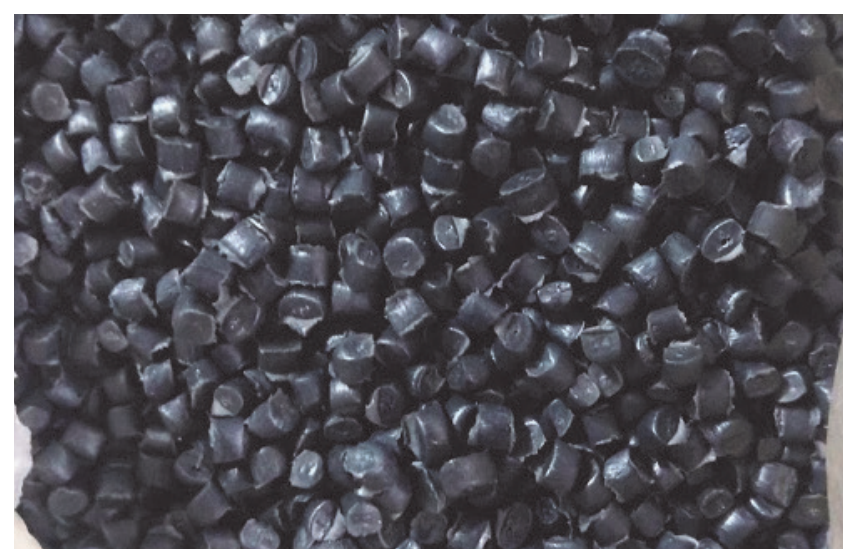

Figura 04 - PEBD Reciclado Granulado na cor preta. Fonte: elaborado pelo autor

Já o processo de aglutinação, é feito em uma linha alternativa. O mesmo material, após ser lavado, secado e triturado é direcionado para um equipamento chamado aglutinador. Nessa máquina, através de alta rotação e atrito do material plástico com placas de metal, transforma-se o material plástico triturado em material plástico aglutinado, deixando-o fisicamente parecido com um pó. Após este processo, este material aglutinado passa em outro modelo de máquina Extrusora Recicladora onde é transformado em grão (Figura 5) pelo mesmo processo de fusão.

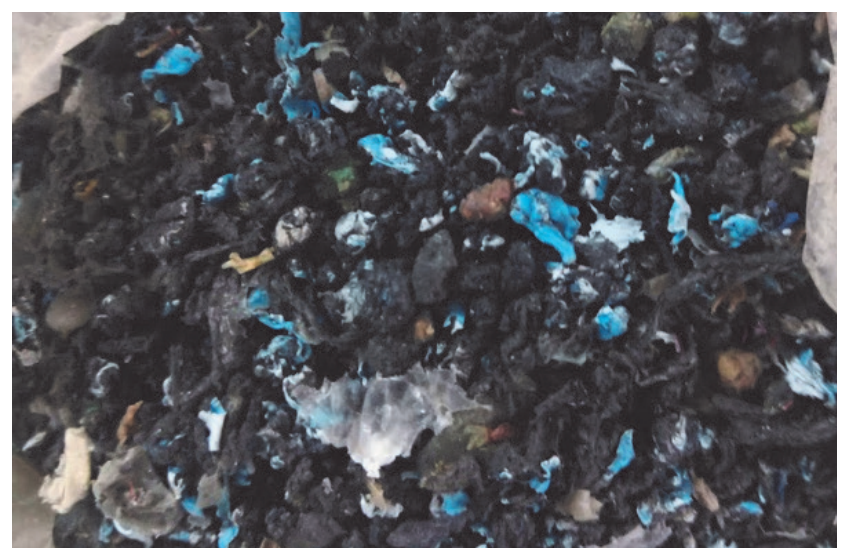

Figura 05 - PEBD Reciclado Aglutinado. Fonte: elaborado pelo autor.

A preparação dos corpos de prova utilizando o material granulado e aglutinado se deu a partir da separação das porções referente a porcentagem de volume do molde, conforme pré-testes, as porcentagens testadas foram: $5 \%, 10 \%, 20 \%, 30 \%, 40 \%, 50 \%$ e $60 \%$ para cada material. Da mesma forma, foram produzidos 5 corpos de prova para cada porcentagem, totalizando 70 amostras. Foram testadas também dosagens de água diferentes as indicadas pelo fabricante, são elas $150 \mathrm{ml} / \mathrm{kg}, 200 \mathrm{ml} / \mathrm{kg}$ e $225 \mathrm{ml} /$ kg, somando 15 corpos de prova. Porém, para análise visual e pesagem, foram utilizadas as 70 amostras produzidas com rejeito granulado e aglutinado, não sendo avaliadas amostras com granulado produzido em ambiente doméstico, e amostras para dosagem de água.

Para pesar os corpos de prova e avaliar a perda de massa das amostras devido a adição do rejeito plástico foi utilizada uma balança digital MARK M2202, da marca Solotest, com capacidade máxima de $2200 \mathrm{~g}$, capacidade mínima 0,5g e margem de erro de 0,1g.

\subsection{Métodos aplicados no experimento}

As amostras cilíndricas foram produzidas conforme a proporção informada na norma ABNT NBR 5738:2003/ABNT NBR 5738:2015, com dimensões de $5 \mathrm{~cm}$ por $10 \mathrm{~cm}$. Elas foram pesadas para avaliar a perda de massa pela adição de rejeito plástico comparada a amostra $100 \%$ de concreto, sem adição de rejeito.

Realizou-se a avaliação visual para analisar a porosidade das peças produzidas. A análise torna-se necessária, pois se acredita que a adição dos rejeitos plásticos possa 
alterar a aparência do concreto de acordo com a porcentagem adicionada quando comparadas às amostras com $100 \%$ de concreto. Após a realização dos testes e obtenção dos dados, sintetizaram-se os dados em forma de gráficos e quadros, bem como uma comparação com as imagens obtidas no teste visual, avaliando a porosidade e estética do material produzido.

Após a definição da dosagem de água, iniciou-se o processo de produção e cura dos corpos de prova com adição de rejeito plástico granulado e aglutinado. Realizou-se, então, a separação das dosagens de rejeito e a preparação da pasta de concreto. $O$ tempo de cura foi de sete dias e, neste período, realizou-se o controle meteorológico. A umidade relativa média, neste período, foi de $77 \%$, alternando entre $62 \%$ e $93 \%$, bem como a temperatura que variou entre $18^{\circ}$ e $25^{\circ}$.

Ao sétimo dia, os 70 corpos de prova foram pesados e selecionou-se 3 amostras de cada porcentagem para realização dos testes de avaliação visual. O processo de pesagem constitui-se em organizar as amostras na bancada (Figura 6) divididas por tipo de rejeito e porcentagem de plástico e pesá-las uma a uma, limpando sempre a bandeja da balança entre uma pesagem e outra e iniciando sempre com a contagem em zero. $O$ processo foi repetido duas vezes por amostra a fim de confirmar os dados obtidos.

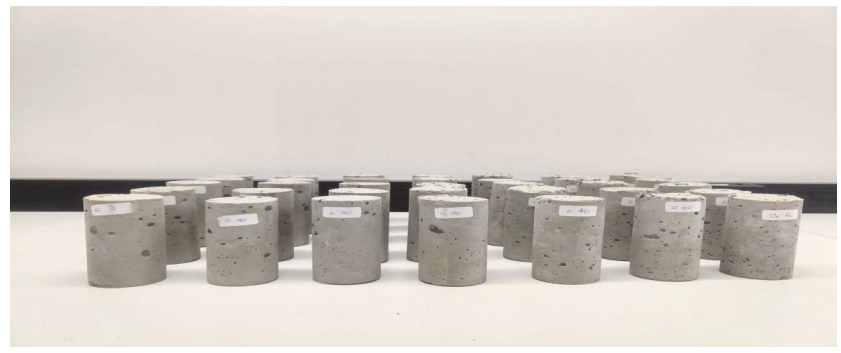

Figura 06 - Amostras antes da pesagem - Grupo de amostras: PEBD Granulado. Fonte: elaborado pelo autor.

Os testes realizados para o experimento e análises foram:

1) Teste de verificação de massa: consiste na pesagem dos corpos de prova (Figura 7) para verificar a possível perda de massa do concreto ao ser produzido com diferentes porcentagens de plástico. Visa observar se a adição de rejeito plástico produz um objeto de concreto mais leve e o quão significativa foi essa diferença entre as amostras $100 \%$ concreto e as amostras com adição do rejeito plástico reciclado granulado e aglutinado.

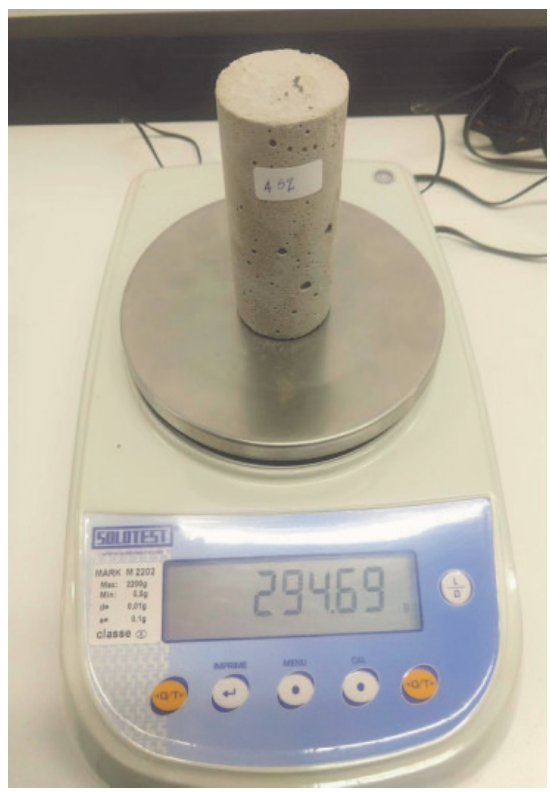

Figura 07 - Pesagem do corpo de prova n. 3 com adição de 5\% de PEBD aglutinado. Fonte: elaborado pelo autor.

2) Avaliação visual: visa analisar diferenças entre a amostra 100\% concreto e as amostras com adição de rejeito plástico. Neste procedimento, foram fotografadas as amostras após pesagem. As fotos foram tiradas de todas as amostras, utilizando a mesma configuração de câmera (Figura 8), em um mesmo local, com mesma incidência de luz. A finalidade é comparar as amostras com adição de rejeito plástico com a amostra de concreto puro, analisando também se a quantidade de rejeito adicionado interfere na superfície da amostra, através da porosidade e também se o rejeito torna-se visível no corpo de prova.

A abertura utilizada para as fotos foi de $\mathrm{f} / 2,0$, a velocidade do obturador 1/30 e ISO médio 62. Para a abertura, quanto menor o número, maior a abertura, logo, passa mais luz. A velocidade diz respeito ao tempo utilizado pelo sensor para capturar a imagem, nestes casos 0,03 segundo. O ISO determina a sensibilidade à luz do sensor que captura a imagem.

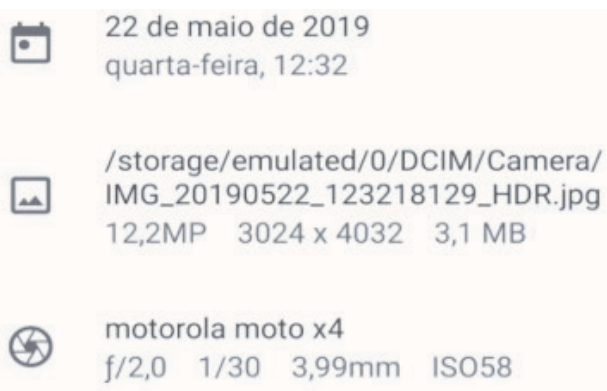

Figura 08 - Configuração câmera para imagens de avaliação visual Fonte: elaborado pelo autor. 
A abertura utilizada para as fotos foi de $\mathrm{f} / 2,0$, a velocidade do obturador 1/30 e ISO médio 62. Para a abertura, quanto menor o número, maior a abertura, logo, passa mais luz. A velocidade diz respeito ao tempo utilizado pelo sensor para capturar a imagem, nestes casos 0,03 segundo. O ISO determina a sensibilidade à luz do sensor que captura a imagem.

\section{RESULTADOS E DISCUSSÕES}

\subsection{Resultados e análise dos testes realizados no experimento}

Nessa seção, são expostos os resultados dos testes realizados nas amostras cilíndricas.

1) Resultados do teste de verificação de massa: conforme descrito nas seções anteriores, foram pesadas todas as amostras produzidas com rejeito plástico reciclado granulado e aglutinado. Para comparar os dados, foram produzidas e pesadas 5 amostras (Tabela 1) compostas apenas pela mistura da argamassa com água (concreto). Essas amostras também perpassaram pela avaliação visual. Os dados obtidos da pesagem dessas amostras apresentam valor médio de $323,51 \mathrm{~g}$ e desvio padrão de $4,81 \mathrm{~g}$ (Tabela 1).

\begin{tabular}{|l|l|l|l|l|l|}
\hline Identificação da amostra & \multicolumn{4}{l|}{ Peso (g) } \\
\cline { 2 - 6 } & CP: 1 & CP: 2 & CP: 3 & CP: 4 & CP: 5 \\
\hline $100 \%$ concreto & 323,5 & 321,0 & 330,3 & 317,7 & 329,3 \\
\hline
\end{tabular}

Tabela 01 - Peso $(\mathrm{g})$ das amostras $100 \%$ concreto. Fonte: elaborado pelo autor.

Nas amostras contendo porcentagem de plástico, os dados obtidos são apresentados nas Tabelas 2 e 3, a fim de tornar visível a diferença entre as dosagens de plástico e, então, comparar os dados obtidos entre as amostras com e sem adição de rejeito (100\% concreto).

\begin{tabular}{|c|c|c|c|c|c|c|}
\hline \multirow{3}{*}{$\begin{array}{l}\% \text { de } \\
\text { resíduo } \\
\text { plástico }\end{array}$} & \multicolumn{6}{|c|}{ Peso (g) } \\
\hline & \multicolumn{5}{|c|}{ Granulado } & \multirow[t]{2}{*}{ Média \pm DP } \\
\hline & $C P: 1$ & $C P: 2$ & $C P: 3$ & CP: 4 & CP:5 & \\
\hline $5 \%$ & 299,8 & 300,6 & 301,5 & 292,7 & 288,4 & $299,8 \pm 5,15$ \\
\hline $10 \%$ & 290,7 & 293,6 & 296,7 & 294,3 & 289,3 & $293,6 \pm 2,64$ \\
\hline $20 \%$ & 280,5 & 281,9 & 283,4 & 285,5 & 286,0 & $283,4 \pm 2,10$ \\
\hline $30 \%$ & 283,1 & 287,1 & 273,1 & 286,4 & 286,5 & $286,4 \pm 5,26$ \\
\hline $40 \%$ & 280,6 & 284,2 & 285,6 & 274,9 & 284,4 & $284,2 \pm 3,65$ \\
\hline $50 \%$ & 282,6 & 274,9 & 279,7 & 278,4 & 278,9 & $278,9 \pm 2,50$ \\
\hline $60 \%$ & 260,3 & 248,3 & 256,4 & 257,4 & 256,0 & $256,4 \pm 4,00$ \\
\hline
\end{tabular}

Tabela 02 - Peso (g) das amostras de concreto com os percentuais de resíduos plásticos. Fonte: elaborado pelo autor.

\begin{tabular}{|l|l|l|l|l|l|l|}
\hline \multirow{2}{*}{$\begin{array}{l}\text { \% de } \\
\text { resíduo } \\
\text { plástico }\end{array}$} & \multicolumn{4}{|l|}{ Peso (g) } & \multicolumn{4}{|l|}{ Média \pm DP } \\
\cline { 2 - 6 } & \multicolumn{4}{|l|}{ Aglutinado } & \multicolumn{1}{|l|}{} \\
\cline { 2 - 6 } & CP: 1 & CP:2 & CP:3 & CP:4 & CP:5 & \\
\hline $5 \%$ & 289,7 & 292,1 & 294,6 & 281,2 & 291,1 & $291,1 \pm 4,57$ \\
\hline $10 \%$ & 301,1 & 294,7 & 294,4 & 290,8 & 292,3 & $294,4 \pm 3,51$ \\
\hline $20 \%$ & 300,2 & 300,8 & 300,7 & 290,7 & 293,1 & $300,2 \pm 4,32$ \\
\hline $30 \%$ & 281,2 & 280,3 & 284,3 & 273,6 & 281,2 & $281,2 \pm 3,54$ \\
\hline $40 \%$ & 267,2 & 268,4 & 269,4 & 269,5 & 269,5 & $269,4 \pm 0,92$ \\
\hline $50 \%$ & 274,8 & 272,7 & 272,9 & 274,2 & 273,5 & $273,5 \pm 0,79$ \\
\hline $60 \%$ & 274,6 & 270,6 & 269,0 & 272,9 & 277,2 & $272,9 \pm 2,91$ \\
\hline
\end{tabular}

Tabela 03 - Peso $(\mathrm{g})$ das amostras de concreto com os percentuais de resíduos plásticos. Fonte: elaborado pelo autor.

O grupo de amostras produzidas com rejeito PEBD granulado apresentou desvio padrão inferior a 5,20g e nas amostras de $10 \%, 20 \%$ e $50 \%$ esse desvio foi inferior a $3,0 \mathrm{~g}$, conforme Tabela 2. Considerando os valores médios, há uma diferença de $14,5 \%$ entre a amostra com $5 \%$ de rejeito e a amostra produzida com $60 \%$ de rejeito, enquanto a diferença entre as médias das amostras de 5 e $30 \%$ de plástico é de $4,5 \%$ do peso do corpo de prova.

Em relação às amostras produzidas com $P E B D$ reciclado aglutinado, o desvio padrão não atingiu valor superior a $4,60 \mathrm{~g}$, apresentando valores abaixo de $1 \mathrm{~g}$ em duas classificações: $40 \%$ e $50 \%$ de adição de PEBD reciclado aglutinado conforme a Tabela 3. Considerando ainda os valores obtidos por meio da média das pesagens de cada grupo de amostras, a diferença entre as amostras de $5 \%$ e $60 \%$ é de $6,3 \%$, enquanto o grupo de amostras produzidas com rejeito granulado apresentou valor superior ao dobro do apresentado pelo grupo de amostras do rejeito aglutinado. Verifica-se, então, que a perda de massa produzindo uma peça de concreto mais leve se deu nas amostras do grupo granulado. Os demais dados relacionados a média e desvio padrão das amostras produzidas com rejeito aglutinado são apresentados abaixo (Tabela 3).

Através da Figura 9, é possível visualizar a comparação dos pesos com as amostras $100 \%$ concreto. Fica perceptível a diferença entre as amostras produzidas com plástico reciclado e as amostras $100 \%$ concreto. A diferença em relação às amostras $100 \%$ concreto e $60 \%$ resíduo plástico é de $15,8 \%$ para as amostras com rejeito granulado, e, 20\% para as amostras com rejeito aglutinado. Porém, mesmo nas amostras $5 \%$, já é possível verificar diferença na pesagem. Nas amostras com PEBD granulado a diferença para as amostras $100 \%$ de argamassa é de $10,2 \%$ e nas amostras aglutinado $7,5 \%$.

Desta forma, confirma-se a hipótese de que o concreto produzido com rejeitos de sacolas plásticas teria diminuição de massa, característica relevante para o uso a que 
se projeta o material proposto. Aliada a perda de massa estão as questões estéticas do material produzido. A seguir, discorre-se sobre a avaliação visual.

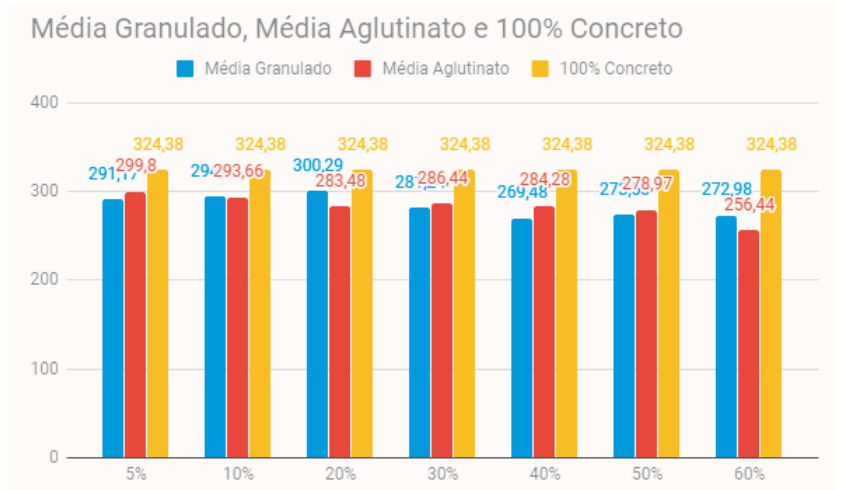

Figura 09 - Peso - Média das amostras produzidas com PEBD reciclado granulado, aglutinado e $100 \%$ concreto.

Fonte: elaborado pelo autor.

2) Resultados da avaliação visual: o objetivo de analisar possíveis alterações na superfície e estética do concreto se dá, pois, a estética do concreto está sendo valorizada no design de interiores, como antevisto neste estudo. Portanto, manter essa estética é um traço importante nessa pesquisa. Para a realização dessa análise, preocupou-se em manter a mesma configuração das fotos a seguir apresentadas, bem como apresentá-las lado a lado para comparação. Os três corpos de prova $100 \%$ concreto, que serviu de referência para essa análise apresentam pouca porosidade e estão bem compactadas.

As Figuras 10 e 11 mostram um quadro de texturas criado a partir de imagens aproximadas de uma amostra de cada grupo, para melhor acompanhar as mudanças acarretadas com o uso do PEBD reciclado granulado e aglutinado. Desta forma, os quadros foram divididos por especificação do rejeito plástico e não mais da dosagem de plástico utilizada nas Figuras anteriores, assim pode-se perceber como cada tipo de rejeito se comportou na composição dos corpos de prova. Para a montagem deste quadro, foi escolhida a primeira amostra de cada dosagem. Somado a esse quadro, está a primeira amostra do grupo composto por amostras 100\% concreto.

Entende-se que bolhas de ar, a porosidade, é uma característica do concreto. Em caráter estético, as amostras $5 \%$ granulado e aglutinado encontram-se de acordo com o esperado, apesar do grande número de poros, que se dá pelo fato dos corpos de prova terem sido produzidos em ambiente doméstico e sem o uso de uma mesa de trepidação. Ainda sim, as amostras apresentaram boa compactação, estética, aproximada à da amostra controle. Uma variável importante neste estudo é a ausência de rejeito na superfície, não alterando sua estética, o que ocorre no topo das amostras 3 e 4 do PEBD granulado e nas amostras 4 e 5 do PEBD aglutinado. Também se verificou que a porosidade apresentada pelas amostras utilizando PEBD aglutinado são inferiores ao outro grupo de amostra. Acredita-se que essa característica deve-se ao tamanho dos grãos do rejeito aglutinado, que, por vezes, é menor ao granulado.

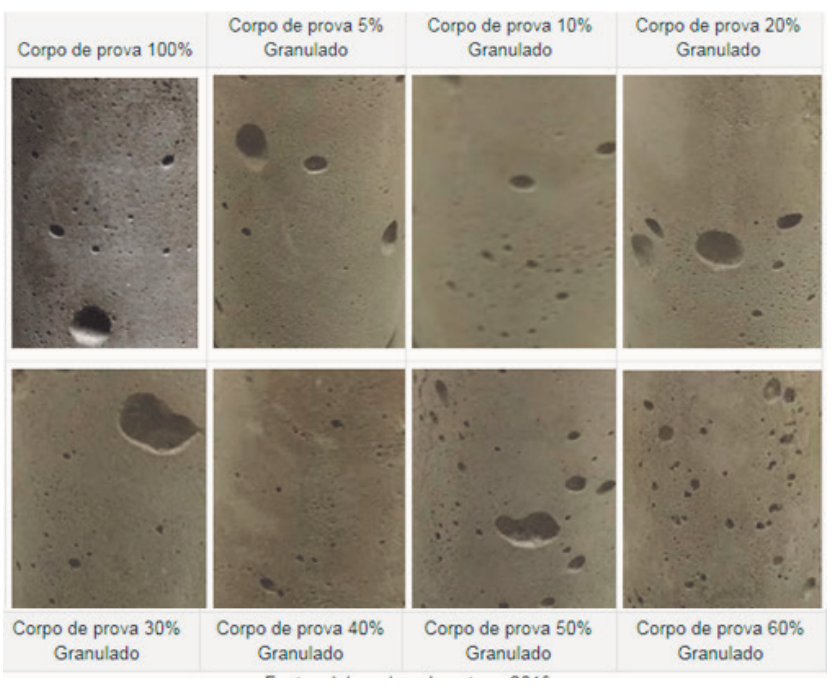

Figura 10 - Avaliação visual - quadro de texturas - PEBD granulado. Fonte: elaborado pelo autor.

Ao analisar as amostras produzidas com 10\% de PEBD, perceberam-se características semelhantes às do grupo de amostras 5\%: maior porosidade nas peças produzidas com rejeito granulado e rejeito visível no topo das amostras, principalmente nas produzidas também com PEBD granulado.

Os grupos de amostra contendo $20 \%$ e $30 \%$ apresentaram estética similar para ambos os rejeitos: pequenos poros e pasta de concreto compacta, próxima ao grupo de controle $100 \%$ concreto, mostrando uma superfície adequada para o uso proposto, assim como os grupos de amostra $5 \%$ e $10 \%$.

As amostras produzidas com $30 \%$ apresentam porosidade semelhante umas às outras, bem como a presença de alguns rejeitos aparentes no topo dos corpos de prova. Características, essas, correlatas aos outros grupos de amostra apresentados. Verificou-se que as seis amostras exibem rejeitos no topo do corpo de prova, porém a superfície segue em concordância com o grupo de controle desta análise.

Os três grupos de amostras a seguir apresentam a maior quantidade de PEBD na sua composição, são elas: $40 \%, 50 \%$ e $60 \%$. Pressupunha-se que a partir dessa 
dosagem de rejeito plástico a superfície da amostra seria alterada, porém, nos grupos de amostras $40 \%$ e $50 \%$, a estética exterior se manteve, aspecto importante nesta avaliação. Seguidamente apresenta-se as Figuras referentes ao grupo de amostras $40 \%$. A diferença notável neste grupo é o topo das amostras, onde o rejeito granulado aparece em maior quantidade.
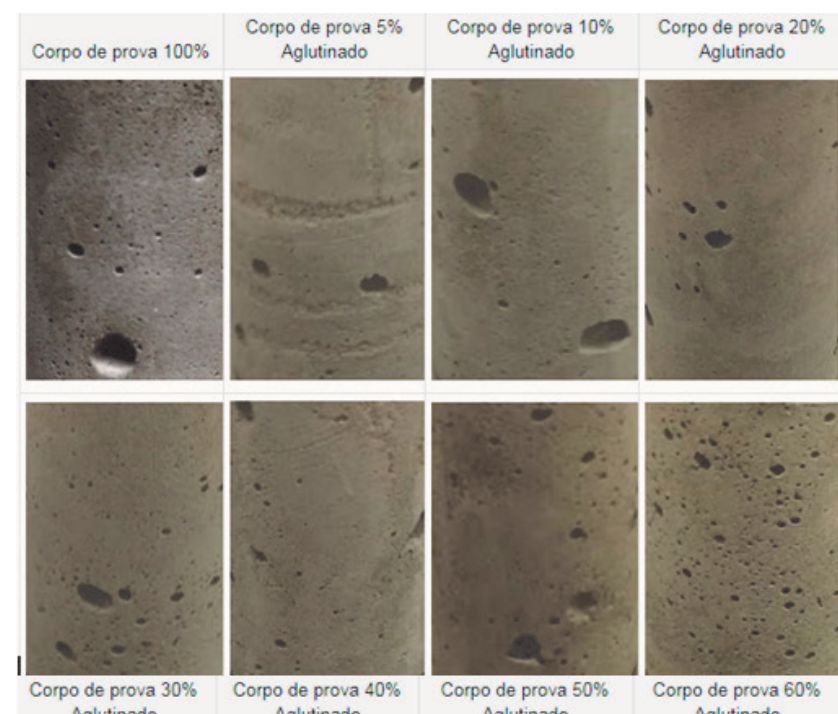
Aglutinado

Aglutinado
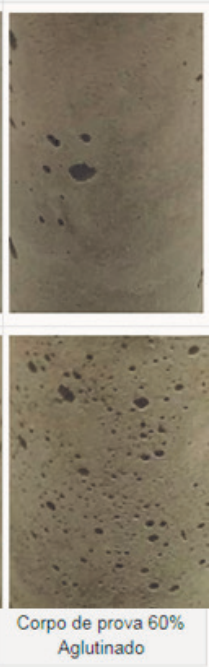

Figura 11 - Avaliação visual - quadro de texturas - PEBD aglutinado. Fonte: elaborado pelo autor.

Os corpos de prova incluindo $50 \%$ do volume da amostra de rejeito plástico mantiveram visual semelhante às demais amostras, com poros de dimensão reduzida se comparado às amostras anteriores, como por exemplo, 5\% e 10\%.

O último grupo de amostras analisado é composto da pasta de argamassa com adição de $60 \%$ do volume do molde de rejeito reciclado. Devido à quantidade de rejeito presente na pasta de concreto, esses corpos de prova apresentaram maior dificuldade no momento de preparação. O volume de PEBD está aparente, principalmente quando comparado aos outros grupos de amostras.

A ausência do rejeito na maior área da amostra é um ponto positivo desta análise, pois havia a hipótese de que os rejeitos ficassem aparentes, alterando a estética do concreto quando comparado ao grupo de amostra controle, sem adição de rejeito nenhum, podendo inviabilizar o uso de tal dosagem.

Analisando os dois quadros de imagens é possível verificar como a estética do concreto se manteve e como são semelhantes às amostras produzidas com os dois tipos de rejeitos - granulado e aglutinado - mesmo que com a adição de maior dosagem a porosidade cresça. Os corpos de prova com dosagem $60 \%$ rejeito são, nos dois grupos, os que mais apresentam pequenos poros, por toda a amostra, por outro lado, as amostras com menor dosagem de plástico apresentam poros de tamanho maior.

Constatou-se que nas dosagens propostas e aqui apresentadas o rejeito plástico não interfere negativamente na estética do concreto, conforme isso inicialmente era esperado.

\section{CONSIDERAÇÕES FINAIS}

Neste estudo, realizou-se uma pesquisa experimental de caráter quantitativo, que, através de testes de pesagem e avaliação visual, investigou a questões estéticas do concreto produzido com diferentes dosagens de rejeito de sacolas plásticas, PEBD reciclado aglutinado e granulado para o uso em objetos de decoração. Para tal, aplicou-se a metodologia quantitativa, a partir do método de pesquisa experimental.

Conclui-se que, segundo os métodos aplicados e testes realizados, o concreto produzido com rejeitos de sacolas plásticas, neste caso de produção industrial, possui massa menor em comparação ao concreto referência, tornando-se um concreto mais leve, característica de expressiva importância para o uso em objetos de decoração, possibilitando, por exemplo, sua manipulação com maior facilidade.

A adição de rejeito plástico reciclado granulado e aglutinado manteve a aparência do concreto sem aparição de rejeito na superfície até a dosagem $40 \%$, bem como uma porosidade equivalente do concreto se manteve em todas as amostras. Acredita-se que para corpos de prova produzidos em laboratório os resultados possam apresentar diferença, porém, o proposto aqui é a produção em ambiente doméstico para representar um movimento verificado através de prévia pesquisa sobre vídeos de "faça você mesmo".

A preocupação com a fonte e escolha de materiais para a pesquisa, bem como o seu descarte e reciclagem após os testes condiz com o problema do aumento exponencial na produção de plásticos e sua incorreta destinação após consumo, com evidente impacto ambiental, principalmente em ambientes e organismos marinhos. Todos os estudos bibliográficos levantados para esta pesquisa também tornaram evidente a necessidade de pensar as escolhas desde o momento do projeto até o descarte.

\section{REFERÊNCIAS}

AMOROZO, Guilherme. Arquitetura e design que melhoram o planeta pautam a Casa Vogue de março. Disponível em: https://casavogue.globo.com/ Interiores/noticia/2019/03/arquitetura-e-design-que-melhoram-o-planeta-pautam-casa-vogue-de-marco.html. Acesso em: 12 out. 2018. 
ASSOCIAÇÃO BRASILEIRA DE NORMAS TÉCNICAS. Projeto de estruturas de concreto - Procedimento: NBR 6118. Rio de Janeiro: ABNT, 2004.

AZAMBUJA, J. A. Sustentabilidade na construção: Em busca de um novo paradigma. Porto Alegre: Editora UniRitter, 2014.

CÂNDIDO, L. H. A. Contribuição ao estudo da reutilização, redução e da reciclagem dos materiais com aplicação do ecodesign. Porto Alegre, 2008.

CHIMELLO, G. Cenoura pode deixar concreto mais forte. Disponível em: https://casavogue.globo.com/ Arquitetura/Edificios/noticia/2018/08/cenoura-pode-deixar-concreto-mais-forte.html. Acesso em: 12 out. 2018.

Do.edu. Relógio de Concreto Como fazer - DIY - Passo a Passo. Disponível em: <https://doedu.co/relogio-concreto-como-fazer-diy/>. Acesso em: 28 set. 2018. EDWARDS, B. O guia básico para a sustentabilidade. Barcelona: Editorial Gustavo Gili, SL, 2008.

HOMEMADEMODERN. Disponível em: http://www.homemade-modern.com/about-why-we-create/. Acesso em 20 out. 2018.

IBRACON. Disponível em: http://site.ibracon.org.br/. Acesso em: 15 out. 2018.

ISOLDI, R. A. Tradição, inovação e sustentabilidade: desafios e perspectivas do projeto sustentável em arquitetura e construção. 2007. 334 f. Tese (Doutorado) - Curso de Engenharia Civil, Universidade Federal do Rio Grande do Sul, Porto Alegre, 2007.

MANZINI, E.; VEZZOLI, C. O Desenvolvimento de Produtos Sustentáveis: os requisitos ambientais dos produtos industriais. São Paulo: Editora da Universidade de São Paulo, 2005.

MICHAELI W.; GREIF H.; KAUFMANN H. Tecnologia dos plásticos. São Paulo: Edgard Blucher, 1995.

PLATCHECK, E. R. Metodologia de ecodesign para o desenvolvimento de produtos sustentáveis. Porto Alegre, 2003.

PREFEITURA DE TRAMANDAÍ. Quantidade de lixo retirado de boca de lobo impressiona. Tramandaí, 28 maio 2019. Disponível em: https://www.facebook.com/prefeituradetramandai/posts/2249790142004730. Acesso em: 28 maio 2019.

REVISTA MINHA CASA. Disponível em: https://minhacasa.abril.com.br. Acesso em: 26 out. 2017.

ROAF, S.; FUENTES, M.; THOMAS-REES, S. Ecohouse: a casa ambientalmente sustentável. Porto Alegre: Bookman, 2014.

SAMPIERI, R. H.; COLLADO, C. F.; LUCIO, M. D. P. B.
Metodologia de Pesquisa. São Paulo: Penso Editora LTDA, 2013.

THACKARA, J. Plano B: o design e as alternativas viáveis em um mundo complexo. São Paulo: Saraiva: Versar, 2008.

TRIGUEIRO, A. Meio ambiente no século 21: 21 especialistas falam da questão ambiental nas suas áreas do conhecimento. Rio de Janeiro: Sextante, 2003.

TRIGUEIRO, A. Mundo sustentável 2: novos rumos para um planeta em crise. São Paulo: Globo, 2012.

VENZKE, C. S. A situação do Ecodesign em empresas moveleiras da região de Bento Gonçalves, RS: Análise da postura e das práticas ambientais. Porto Alegre, 2002. Dissertação (Mestrado) - Curso de Administração, Universidade Federal do Rio Grande do Sul, Porto Alegre, 2002.

WOLFFENBÜTTEL, R. F. Sustentabilidade e ação socioeconômica: a rede produtiva do plástico verde. Porto Alegre, 2015.

ZYLBERSZTAJN, D.; LINS, C. Sustentabilidade e geração de valor: a transição para o século XXI. Rio de Janeiro: Elsevier, 2010. 


\section{AUTORES}

ORCID: $\quad 0000-0001-9255-9263$ e https://orcid. org/0000-0001-9255-9263

BIBIANA WITTMANN LANZARIN, M.Sc. | UniRitter | Correspondência para: Rua São Francisco de Assis, 505 Oásis Sul, Tramandaí - RS, 95590-000 | e-mail: bibianaw. design@gmail.com

ORCID: $\quad 0000-0002-3829-496 \mathrm{X}$ e https://orcid. org/0000-0002-3829-496X

LUIS FERNANDO FOLLE, Dr. | UFRGS, PPGE3M, PORTO ALEGRE RS - BRASIL | Correspondência para: Rua Dr Barcelos, 930, Ap 206 - Tristeza, Porto Alegre - RS, 91910-251 | E-mail: folle.luis@gmail.com

\section{COMO CITAR ESTE ARTIGO}

LANZARIN, Bibiana Wittmann; FOLLE, Luis Fernando. Análise da Estética do Concreto Produzido com Rejeito Plástico para o Uso no Design de Interiores com Viés Sustentável. MIX Sustentável, [S.I.], v. 6, n. 4, p. 61-72, ago. 2020. ISSN 24473073. Disponível em:<http://www.nexos.ufsc.br/index.php/mixsustentavel>. Acesso em: dia mês. ano. doi:https://doi. org/10.29183/2447-3073.MIX2020.v6.n4.61-72

DATA DE ENVI0: 03/12/2019

DATA DE ACEITE: $25 / 06 / 2020$ 